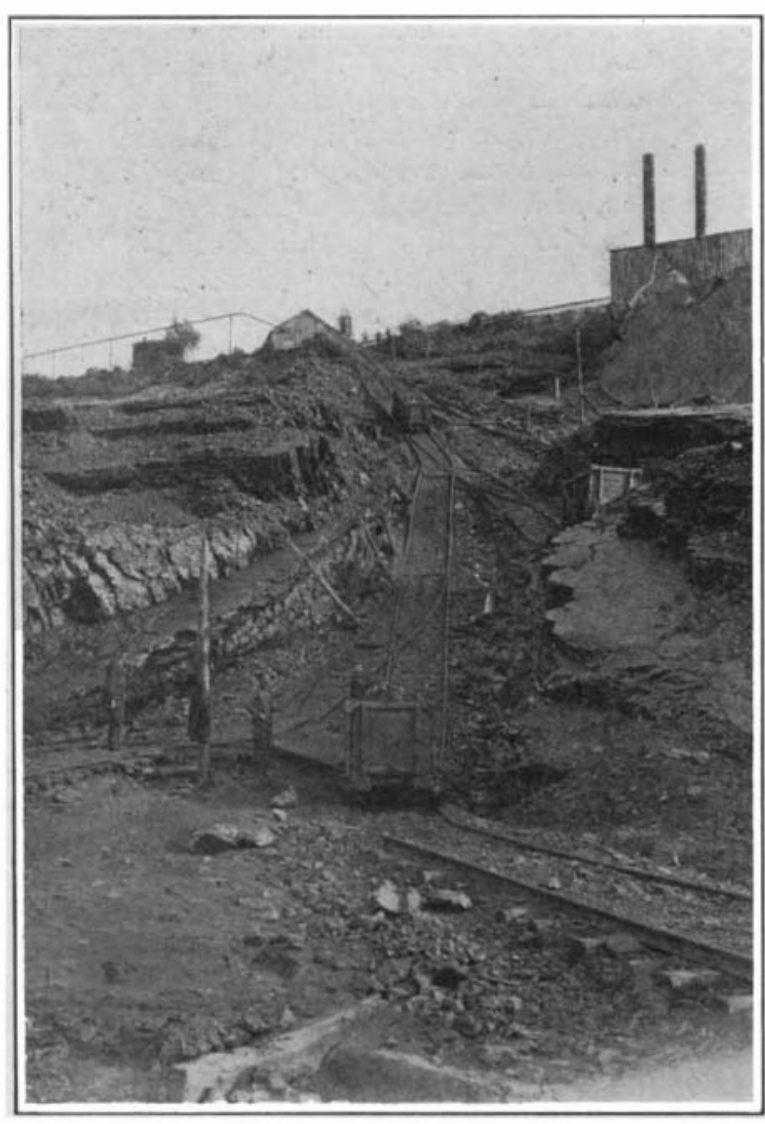

Hoisting plane leading out of the Drifton stripping.

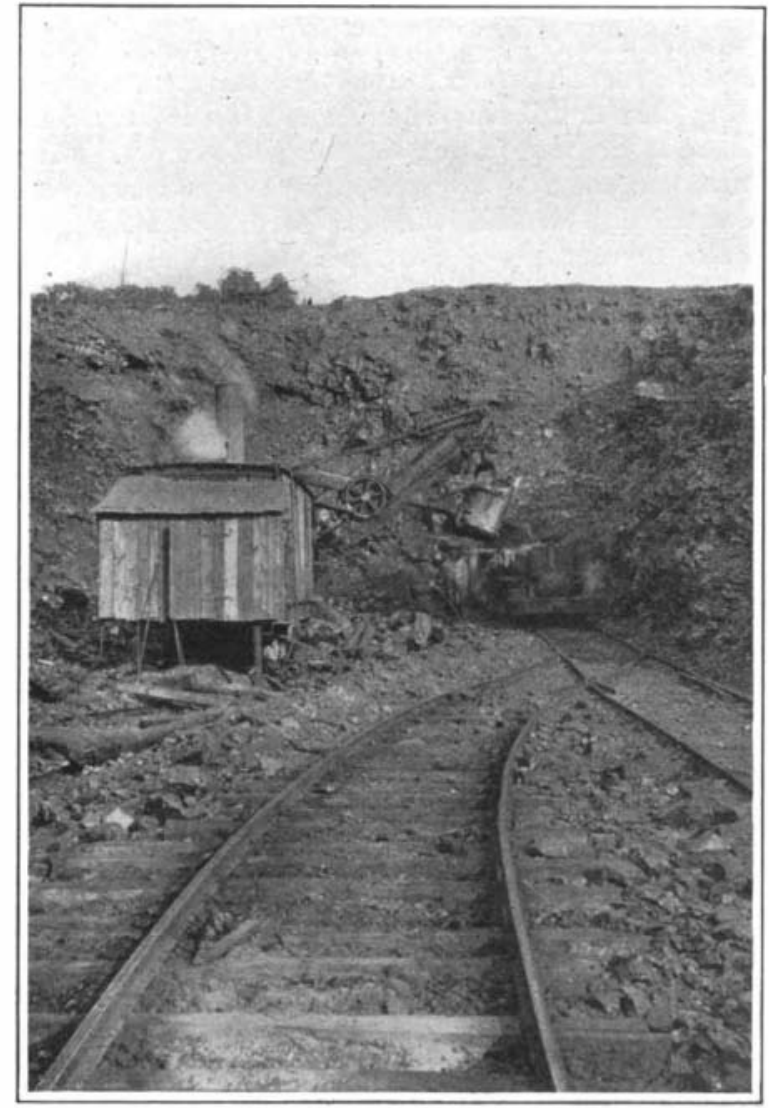

Small locomotive or "lokey" and steam shovel at work.

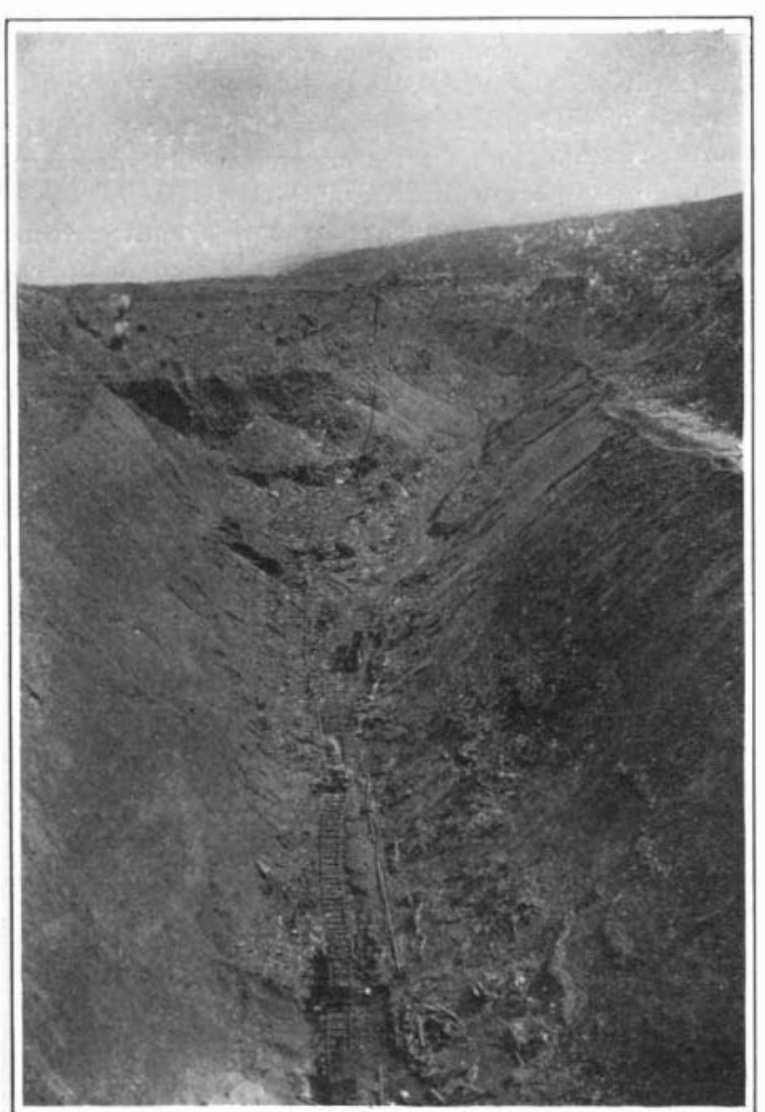

Big enough to look like the Panama Canal.

\title{
Open Air Coal Mining
}

\section{Stripping Methods Employed in the Anthracite Coal Region of Pennsylvania}

By E. J. D. Coxe

The Anthracite Coal Region of Pennsylvania, owing to the geological conditions that brought about its formation, presents many problems to the mining enginee that do not exist in any other producing coal region of the world. The tremendous contortion of the strat which has changed the flat-lying bituminous coal beds into anthracite or "natural coke" by means of heat and into anthracite or "ntural coke" enormous preser ing difficulties encountered. The great variation in thickness of the different coal beds or "veins" also raise problems that the bituminous mines in this country do not encounter.

Since comparatively early times in the history of anthracite coal mining, "stripping," or the removal of th top cover of shallow-lying coal beds, has been used as a method of mining in the anthracite reaion; but with the method of mining in the anch the develop duced the cost or excavation, stipping has in recent years become a more and more important method of mining. The economy of stripping over underground mining is twofold. In the first place, after the cover has been removed all coal in the bed becomes available, and 100 pe cent goes to market instead of having to leave from 15 to 40 per cent in the ground, as is necessary in underground mining. In the second place, the coal can be mined by a steam-shovel at a small fraction of the labor mined by a steam-shovel at a small fraction of the labo cost of underground work. The expense of stripping of course lies in the very great. first cost of removal of the top cover. The question "Whether it will pay" to strip a given tract is often a very delicate one for the engineer to decide, but the improvement in excavation methods in recent years has greatly increased the amount of cover that can be removed for a given quantity of coal. In some cases 4 feet of rock are removed to uncover 1 foot of coal, or in other words, 160 feet of rock is excavated to uncover a 40-foot coal bed. An elaborate exploration of the rock and coal strata involved, with the aid of the diamond drill, is the only method by which the engineer may obtain proper data before deciding for or against the stripping method of development.

Strippings are of two general types, those which uncover only a portion of the coal bed where it approaches the surface, or "out-crops," and those in which the entire coal bed, or "basin," is stripped. In the former case the coal is usually removed through the underground workings of the same vein, which are too deep to strip. Strippings of the second class are much larger operations. Several at present in operation in the Lehigh or Middle Anthracite field are big enough to look like sections of the Panama Canal.

The largest stripping in existence is at the Drifton colliery of Coxe Bros. \& Co., Inc. Fig. 1 shows a sketch map of the work at present, and Fig. 2 shows a north and south cross section of the formation through the western end of the stripping. As in all other coal basins of the Middle or Lehigh district the coal beds here lie in long narrow "canoe-shaped" basins of varying width and depth, the long axis of the basin running in a north-ofeast to south-of-west direction. The most important col in col to bottom, are "Whe "Mam" tok" thick; the "Wharton" bed, 6 to 7 feet thick; the "Gamma," which is rather irregular and in some places unworkable, but averages about 3 feet in thickness; and the "Buck Mountain" bed, from 12 to 16 feet thick. The last named, on account of its being very much deeper than the others, covers a much greater acreage between its out-crops, but of course for the same reason is not suitable for stripping operations except at certain points near the out-crop. On the western portion of the Drifton basin the Mammoth and Wharton beds are only separated by a thin stratum of rock from 2 to 3 feet thick, as will be seen by reference to the cross section, and as will be seen by sufficiently approach the surface so that stripping operations are possible. The stripping is treme western end of the Drifton tract of the Tench Coxe estate, the coal basin extending to the west under the land of the Lattimer colliery of Pardee \& Co., who also strip the Mammoth seam on their property. One of the photographs shows a view of the western end of the Drifton stripping, taken from the top of the hoisting plane, with the "barrier pillar" between the Drifton and Iattimer the "bow timer tracts show pol that has been left standing for the present, as the tunnel under it forms a convenient "round house" for the small locomotives or "lokeys," that tend the steam-shovels.

The earth and rock excavation of strippings is usually let out under contract to stripping contractors. After the cover has been removed the coal companies handle the excavation or mining of the coal themselves. Several of the rock-shovels now in operation are capable of handre tons of rock at a load. A the Mammoth seam averages about 35 feet in thickness, with the Wharton seam 6 feet below it, and with only 2 feet of rock between. Thus the stripping lays bare about 41 feet of available coal. As will be seen from the map, the operation is over 800 feet broad at its widest point and 2,000 feet long. The greatest depth to the coal

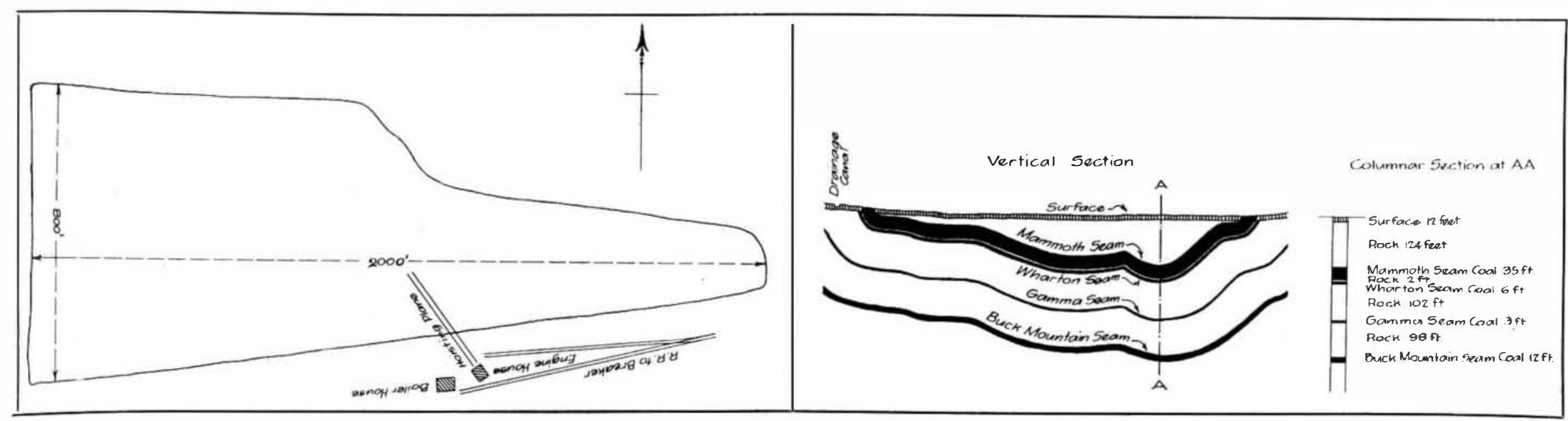

Fig. 1.-Sketch map showing the general lay-out of the stripping at Drifton Colliery.
Fig. 2.-North and south cross section of coal bed formation through western end of stripping. 
is about 140 feet and the excavation will be 180 feet deep after the coal is removed. The detrital surface materia is about 12 feet thick and the rest of the cover is rock. The total excavation of cover (surface and rock) to date is a little over 3,000,000 cubic yards, which has laid bare about 1,700,000 tons of coal.

The "Gamma" and "Buck Mountain" beds of coal are mined by underground methods, under the area covered by this stripping, as their depth is too great to make stripping them practicable.

The method of mining the coal in the strippings consists of blasting the coal in large sections by gangs of men working ahead of the steam-shovel, which then loads it into mine cars brought to the shovel by little "minelokeys." The shovel is able to load about 500 mine cars of three and one half tons capacity each in a working day. After the trip of cars is loaded the lokey hauls them to the foot of the hoisting plane, where they are hoisted two at a time to the surface. They are then hauled by larger locomotives in trips of about twenty cars each to the breaker, about three and a half miles away. This "breaker" handles all the coal from the Drifton colliery, which includes four underground mines besides the stripping.

The method of blasting coal in advance of the steamshovel is of interest. A series of holes is drilled, usually by steam drills, from the surface of the exposed coal through to bed rock. At the bottom of each hole a charge of dynamite, called a "leader-blast," is exploded. This does not break up the coal strata, but shatters a small pocket of coal at the bottom of each hole. Each hole is then filled with water and a small charge of dynamite is sunk through the resulting mass of fine coal and water to the bottom of the bole. This charge is then exploded, which "clan" the hole, throwing out all the col di which "cleans" the hole, throwing out all the coal dirt each hole (and against the bed rocks) are then filled with black powder. Several of these holes are then fired simultaneously, the result being that the entire area of coal is "loosened up" ready for the steam-shovel. In a single blast made recently at the Drifton stripping eleven holes were bared and twenty-five sticks of 40 per cent dynamite exploded in each hole as a "leader blast." In the resulting cavities from ten to fifteen kegs of black powder were placed in each hole, and the eleven holes fired together. The resulting explosion "brought down" six thousand mine-carloads of coal, or approximately 21,000 tons.

One great advantage of this method of blasting is that while breaking up the coal sufficiently for convenient handling by the steam-shovel, it reduces to a minimum the percentage of fine sizes. There is very little "dirt" produced and a very large proportion of the coal goes to the breaker in large lumps.

\title{
Bird Calling*
}

\section{An Attractive Art for Lovers of Nature}

\author{
By W. A. Nicholson
}

THE art of attracting wild birds is one little known or understood except by those whose special interest lies in this direction. The bird-catchers, and those who trade in live birds, understand little, if anything, about this subject, and even the bird-catchers themselves seldom practise it, relying almost solely upon of various patterns in my possession, that I make use of regularly, there is quite a collection of different kinds, a total of eighteen being here represented. It is at all times advisable to procure the very best that are made, for the simple reason that with care they give the finest results and will last for many years.

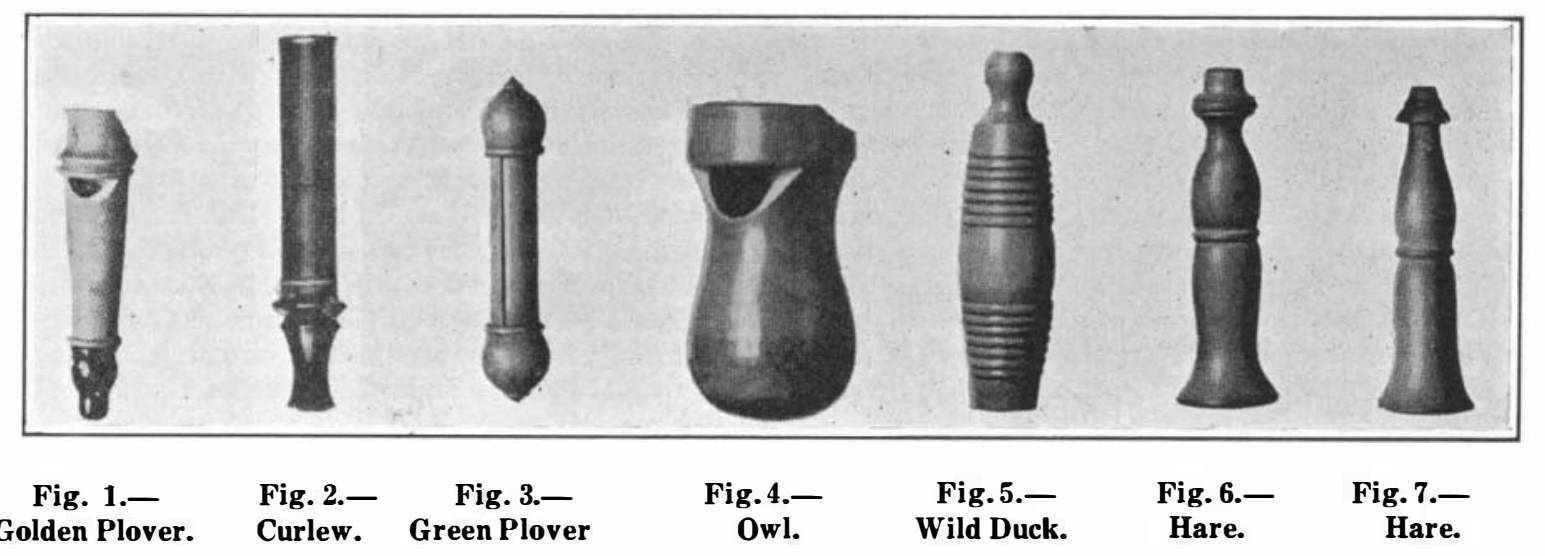

the live decoys shut up in small cages wherewith to attract their wild companions to the deadly limed twigs. One must be well versed and possess a thorough knowledge of the notes emitted by birds, besides being acquainted with their habits, before he can employ the aid of calls with success, and the professional birdcatcher is an individual of too indolent a character or this work, which, doubtless, is the principal reason he leaves it severely alone. Those who use bird-calls regularly are the bird-photographer, the field naturalist and the wild-fowler, and all with the one object and main purpose of decoying the species and making them come nearer the first to enable him to secure a good come poure a good nerative and larger picture, the second, to extend his nowledge of the habits of a species; and the third, to secure the specimen. The wild-fowler, however, makes use of few calls, often not more than six, these
usually being those imitating the cry of the wild duck usually being those imitating the cry of the wild duck
(mallard-see Fig. 5), curlew (see Fig. 2), golden plover (mallard-see Fig. 5), curlew (see Fig. 2), golden plover
(see Fig. 1), green plover (see Fig. 3), wigeon and teal (see Figs. 18, 15 and 9), and often two only are regularly carried, these being the calls of the golden plover and curlew. As will be observed from the illustrations which have been reproduced from photographs tons which have been reproduced from photograph *Reproduced from Knowledge.

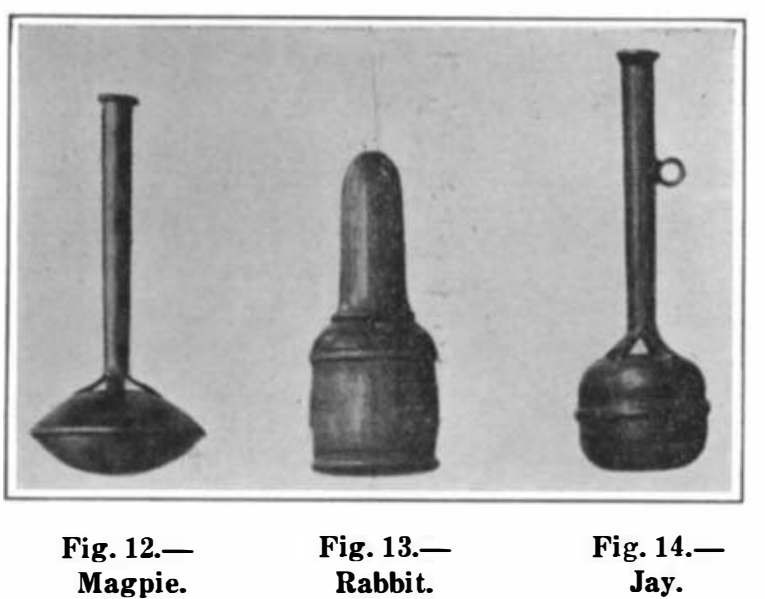

As remarked above, the successful use of these calls chiefly depends upon the operator and his practical knowledge of the proper notes emitted by the birds in a wild state, and without experience of the latter it will be only time waster to it will be only time wasted to late them, except, perhaps, with the exception of two of the instruments, namely, that of the wood-pigeon (see Fig. 17) and the golden plover (see Fig. 1). These two are the simplest to operate and little practice is necessary to enable one to make successful use of them. The wood pigeon call may also be substituted for that of the cuckoo, and a little practice with it soon enables one to acquire the correct pitch and modulation of sound necessary. It is very interesting to visit a breeding baunt of the wood pigeon with on ing haunt of the wood pigeon with one of these calls. My method is to conceal myself (I use a biding tent for this purpose, which is furnished with tapes, to
which I attach twigs, grass, and so on, and make use which I attach twigs, grass, and so on, and make use
of the surrounding undergrowth to screen it) under the nesting trees, having previously arranged my camera in position, and send out a few nates. As generally happens, the cushats in the immediate neighborhood are cooing all around, and, at first, little or no notice is taken by the birds of one's efforts, but the secret is to continue to call, not, however, uninteruptsecret is to continue to call, not, howover, uninterruptedly, but with pauses of about four minutes, making a fairly high pitch in the tone, when the birds will be observed to crane their necks downward and stop cooing. Some bolder than others fly closer to the hidden caller, often approaching to within a few yards, and altogether the call, always assuming the proper sounds are given, has a most alluring effect on wood pigeons during the commencement of one of their breeding periods. During incubation, however, the birds pay

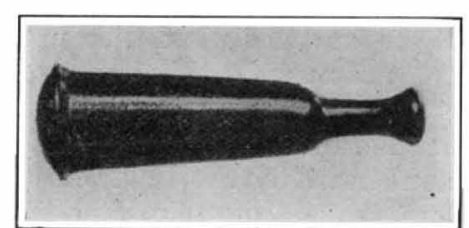

Fig. 15.-Wigeon (improved pattern.) little heed to artificial calls, and at such times it is useless trying to attract them. Another easily duped species is the cuckoo, which may be enticed to within a few feet of the manipulator, and the same may be mentioned of the golden plover (see Fig. 1), partridge (see Fig. 8), pheasant (see Fig. 16), and little grebe

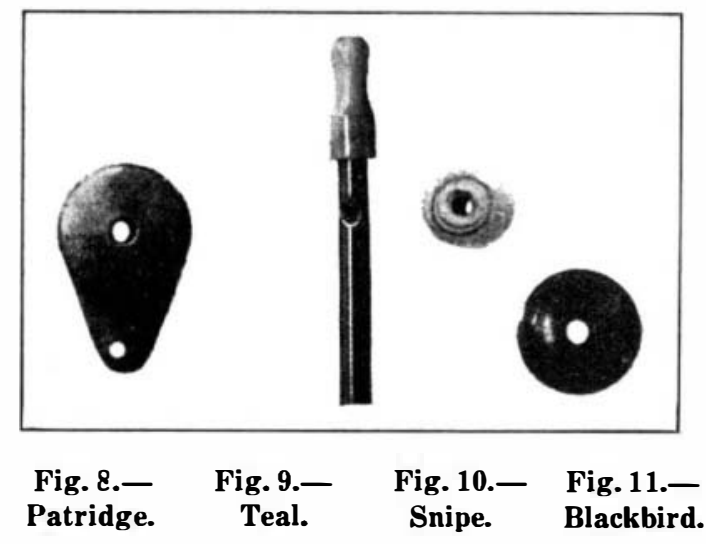

(dabchick). Species somewhat more difficult to deal with are the wild duck (mallard - see Fig. 5), curlew (see Fig. 2), snipe (see Fig. 10), owl (see Fig. 4), wigeon (see Fig. 18), magpie (see Fig. 12), oyster-catcher, and red-throated diver. All the calls illustrated should be worked with with the left hand, so as to leave the right hand free for manipulating the shutter of the camera and other necessary items.

The art of bird-calling here briefly illustrated is a most interesting study, possessing a peculiar charm, a charm impossible to describe, and one having a fondness for ornithological pursuits, and with plenty of time to spare, could hardly do better than take up so absorbing a hobby, the acquisition of which would repay him a thousandfold. But such a one must be puch a one must be possessed of great patience and perseverance, other-
wise failure is certain.

\section{Correction}

In an article entitled "Cellar Space Made Available by the Use of Prismatic Glass." (Supplement Aug. 16, 1913 , p. 107.) certain dimensions were mistated owing to an unfortunate printer's error. In the fifth paraagraph of the second column the dimensions of the areaway should be $4 \times 4$ feet and in the 10th paragraph 2 inches from the ceiling, and 2 to $2 \frac{1}{2}$ inches from the floor should be the same number of feet in each case.

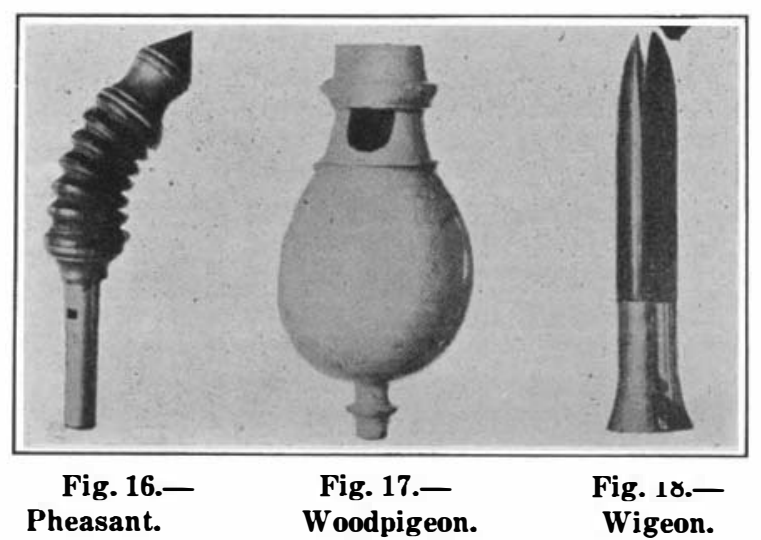

